\title{
Profiles of patients on warfarin anticoagulation therapy in a leading tertiary referral hospital in Kenya; findings and implications for Kenya
}

\author{
David Gitonga Nyamu, BPharm, MPharm, PhD(c) a ${ }^{a^{*}}$, Anastasia Nkatha Guantai, BPharm, MSc, PhD ${ }^{\mathrm{b}}$, \\ George Oyamo Osanjo, BPharm, MSc, PhD ${ }^{b}$, Brian Godman, BSc, PhD ${ }^{\mathrm{c}, \mathrm{d}, \mathrm{e}}$, Eleni Aklillu, BPharm, MSc, \\ $\mathrm{PhD}^{\mathrm{c}}$
}

aDepartment of Pharmaceutics \& Pharmacy Practice, School of Pharmacy, University of Nairobi, P.O. Box 19676-00202 KNH, Nairobi Kenya. Email address: dgnyamu@gmail.com

bDepartment of Pharmacology \& Pharmacognosy, School of Pharmacy, University of Nairobi, P.O. Box 19676-00202 KNH, Kenya. Email: aguantai@yahoo.com; gosanjo@yahoo.com

'Division of Clinical Pharmacology, Karolinska Institute, Karolinska University Hospital Huddinge, Stockholm, Sweden. Emails: Brian.Godman@ki.se; eleni.aklillu@ki.se

dStrathclyde Institute of Pharmacy and Biomedical Sciences, University of Strathclyde, Glasgow G4 ORE, United Kingdom. Email: brian.godman@strath.ac.uk

eDepartment of Pharmacy, Faculty of Health Sciences, Sefako Makgatho Health Sciences University, Pretoria, South Africa

*Author for Correspondence: David G. Nyamu, BPharm, MPharm, PhD(c) Email: [dgnyamu@gmail.com]. Phone: [+254 722 403671]. Senior Lecturer in Clinical Pharmacy, Department of Pharmaceutics and Pharmacy Practice, University of Nairobi, Kenya

(Accepted for publication Expert Review of Cardiovascular Therapy)

\section{ABSTRACT}

Background: Patients' profiles affect the outcome with warfarin; however, this data, and its implications, is scarce in resource-poor countries such as Kenya without access to pharmacogenetics or regular INR testing.

Objectives: To characterize the profiles of patients on long-term warfarin therapy and subsequently use the findings to guide future anticoagulation management.

Methods: Cross-sectional study undertaken among 180 adult patients receiving warfarin therapy in anticoagulation clinics at a leading referral hospital in Kenya. Sociodemographic characteristics were obtained through face-to-face interviews. Details of warfarin therapy, concomitant medication and comorbidities were retrieved from medical records. Associations between patients' profiles and the clinical indications of anticoagulation were computed at $p \leq 0.05$.

Results: Warfarin maintenance dose was $6.17( \pm 2.75) \mathrm{mg}$ per day. Venous thromboembolism $(56.6 \%)$ amongst obese patients $(p=0.0019)$ and cardioembolic events $(48.3 \%)$ among males $(p=0.0316)$ aged $\leq 50$ years $(p=0.0436)$ whose body mass indices were $\leq 25(p<0.0001)$, were the most common indications. Two-fifths and $45.0 \%$ of the patients had at least one other disease and concomitant medications. 
Conclusions: Long term warfarin therapy among Kenyans is mainly for overweight or lean middle-aged individuals suffering from venous or cardioembolic diseases and requires high daily doses. Studies should correlate patients' profiles with warfarin response to guide future management.

Key Words: Warfarin Anticoagulation Therapy, Warfarin, Patient Profiles, Kenya

\section{0: Introduction}

The prevalence of venous thromboembolic events is high in low and middle income countries (LMICs) especially due to increasing hypercoagulable states [1] as well as immobility due to long-term neurological illnesses [2]. Anticoagulation therapy using warfarin is an integral component of long term treatment for patients suffering from venous and cardiac thromboembolic and disorders, and these are still the commonest indications for vitamin $\mathrm{K}$ antagonists [3-5]. Furthermore, coumarins have been shown to be effective in preventing thrombosis in patients with atrial fibrillation [6], heart valve surgeries or repair [7] as well as ischemic stroke in predisposed individuals [8].

Evidence has shown that warfarin is the most commonly used anticoagulation therapy because it reduces morbidity and mortality associated with thromboembolism [4,9]. There has been an increase in the use of direct acting oral anticoagulants in recent years in high income countries [10,11]; however, limited use in lower and middle income countries in view of their high acquisition costs compared to warfarin.

The inter-patient variability in warfarin response and its narrow therapeutic index combined with a high likelihood of warfarin -induced hemorrhagic stroke in patients has restricted its medical use [12-15]. This inter-individual variability in response is mainly attributed to differences in patients' profiles due to factors such as genetic polymorphisms in warfarin metabolizing enzymes in addition to interactions with commonly used medicines and food $[13,16,17]$. For instance, among the Chinese population, the most important inter-patient variability in warfarin response and dose was age, with statistically significant lower warfarin requirements with increasing age [7].

Studies conducted in Kenya have shown that the prescribing of warfarin is commonest among young adults less than 40 years of age [18] and lower in the elderly $[19,20]$. In addition, patients on long term 
anticoagulation therapy were found to have adequate knowledge but poor adherence to warfarin therapy

$[20,21]$.

We have previously reported on potential predictors of adequate warfarin response among Kenyan patients [22] as well as the patterns of anticoagulation management in an urban county government hospital in Kenya [23]. Factors such as patients' sociodemographic characteristics [20], knowledge [24], and drug-drug interactions [5], have also been implicated in the response to warfarin along with pharmacogenetics. In addition, the degree of obesity has been linearly linked to the development of thrombotic events and should increasingly be taken into account when prescribing warfarin [25-27]. This is an increasing concern in Kenya with high rates of overweight and obesity in the population [28-31]. Whilst patient profiling is increasingly seen as vital for optimizing anticoagulation management, there is limited published literature among sub-Saharan African countries including Kenya on the profiles of patients on warfarin therapy to help improve future management. We are aware that Manji et al found that having an artificial heart valve and duration of follow-up of $>120$ days were significantly associated with having a greater time in the therapeutic range (TTR); however, having a venous thromboembolism, a history of tuberculosis, HIV and a duration of follow-up of $<120$ days were associated with having a lower TTR [9]. Concomitant HIV is important as studies undertaken in Kenya have shown the need for extended anticoagulation to achieve therapeutic international normalized ratio (INR) within 21 days [32]. We sought to build on this study to characterize the profiles of patients on long-term warfarin therapy in a leading referral hospital in Kenya where there is no routine funding for pharmacogenetic evaluations and routine assessment of INRs, and subsequently use the findings to discuss their implications in future anticoagulation management. The lack of resources for routine pharmacogenetic testing and INR levels is typical among many lower- and middle-income countries with high patient co-payments and often catastrophic consequences when family members become ill [33-35].

\section{0: Methodology}

\section{$2.1 \quad$ Study Design and Area}

A retrospective cross-sectional study was undertaken from June- December 2018 among adult

outpatients undergoing long term warfarin therapy (>28 days) at anticoagulation clinics of Kenyatta National Hospital $(\mathrm{KNH}) . \mathrm{KNH}$ is the largest teaching and referral hospital in East and Central Africa. The specialized clinics comprise the cardiothoracic, cardiac and haemato-oncology units, and they are the central points for all anticoagulation management in the hospital. The three outpatient clinics are each run once a week on separate days. The cardiac clinic serves patients with cardiovascular disorders such as heart failure and those with atrial fibrillation are usually on prophylactic anticoagulation therapy. The hemato-oncology clinic serves patients on treatment for venous thromboembolic events and those at high risk of developing thrombosis such as patients with cancer. Cardiothoracic clinic serves patients who have undergone heart valve replacement or repair. Patients being discharged from the hospital or referred from peripheral facilities for anticoagulation therapy are managed at these clinics. Consequently, these specialized anticoagulation clinics were seen as the ideal catchment areas for this study. 


\section{$2.2 \quad$ Study Population}

The study population comprised of both males and females aged $\geq 18$ years who were undergoing anticoagulation management and follow up at the study clinics. Those excluded were non-compliant to anticoagulation therapy, pregnant women, patients suffering from mental or psychiatric illnesses as we were concerned they would be unable to provide written informed consent on their own, as well as patients with peptic ulcer disease, uncontrolled hypertension or any coagulation disorders. Patients who were not compliant to treatment were excluded in order not to compromise the profiling.

\subsection{Sample Size and Sampling Method}

The main outcome variable was the prevalence of thromboembolic events requiring long term warfarin therapy in patients at risk. Previous studies have indicated that the prevalence of deep vein thrombosis (DVT) in cancer patients was 15\% [1] and in Egypt, the incidence of DVT among hospitalized patients with stroke was almost $10 \%$ [2]. Using the average (12.5\%) for the two prevalence rates and an equation for the estimation of sample size for such epidemiological surveys, a minimum sample of 168 participants was calculated [36]. However, $5 \%$ was added to allow for data losses to arrive at a minimum sample size of 175 for such a study, which was rounded up to 180 . Patients were recruited consecutively as they came for their clinic appointments until the sample size was achieved.

\section{$2.4 \quad$ Ethical Approval}

Ethical approval was sought from Kenyatta National Hospital/University of Nairobi-Ethics and Research Committee (KNH/UoN-ERC), approved through the reference number $\mathrm{KNH}-\mathrm{ERC} / \mathrm{A} / 569$ and registered by KNH Department of Research and Programs reference number MED/25/14. All other protocols, including seeking the authority to conduct research from the study sites, were also observed before the study begun.

Eligible participants were taken through a detailed consenting process and those who accepted to participate were requested to sign the informed consent document. A predesigned semi-structured questionnaire was subsequently administered to capture the sociodemographic characteristics of patients including their age, gender, highest education level, occupation and marital status. To determine their body mass indices, weight and height measurements were taken and recorded. However, this was not always recorded in previous visits. Details of anticoagulation including the indication of warfarin therapy, 
concomitant medications and comorbidities, initial and maintenance doses of warfarin as well as the duration of its use were retrieved from the patients' files.

\subsection{Data Entry and Statistical Analysis}

A database resembling the questionnaire was created using the IBM Statistical software for social studies version 23. All the raw data from the study questionnaires were directly entered into the database. Each questionnaire had a unique alphanumerical number which was linked to the created database. Frequencies were run to describe the study population in terms of socio-demographic characteristics, clinical indications of warfarin, number of comorbidities as well as the extent of concomitant medications used by the study patients to bar charts for important variables.

Bivariate analysis was conducted to determine associations between the sociodemographic characteristics and the clinical indications of warfarin anticoagulation using Chi-square tests. P-values and $95 \%$ Confidence Interval $(\mathrm{Cl})$ were used to estimate the strength of crude association between predictor and outcome variables. The threshold for statistical significance was set at $\mathrm{P} \leq 0.05$.

\section{0: Results}

Two hundred and five participants were screened. However, data was only analyzed from 180 participants as twenty-five patients were not eligible due to: age $<18$ years $(n=2)$, history of peptic ulceration $(n=6)$, inconsistent use of warfarin $(n=2)$ and missing data in the files $(n=15)$. Table 1 shows the sociodemographics and clinical characteristics of the final number of participants in the study.

Table 1: Sociodemographic Characteristics of the Study Participants

\begin{tabular}{llcc}
\hline Variable & Category & \multicolumn{2}{c}{ All participants (N=180) } \\
& & Frequency(n) & $\begin{array}{c}\text { Percentage } \\
\text { (\%) }\end{array}$ \\
\hline Gender & Male & 42 & 23.3 \\
& Female & $\mathbf{1 3 8}$ & $\mathbf{7 6 . 7}$ \\
\hline Age & 50 and Below years & 131 & 72.8 \\
& Above 50 Years & 49 & 27.2 \\
\hline Age Categories & 18-40 Years & 79 & 43.9 \\
& 41-65 Years & 89 & 49.4 \\
& $>65$ Years & 12 & 6.7 \\
\hline
\end{tabular}




\begin{tabular}{llcc}
\hline Mean/ Median Age & Years & 43.1 $\pm 13.2 ;$ & Median 42.0; (range 18.0-87.0) \\
\hline BMI & Underweight & 11 & 7.4 \\
& Normal Weight & 47 & 31.8 \\
& Overweight/Obese & 90 & 60.8 \\
& Missing & 32 & 17.8 \\
\hline Mean/Median/Range & Height (Meters) & $1.6 \pm 0.1 ;$ Median 1.6; (range 1.2-1.9) \\
\hline Mean/Median/Range & Weight (Kg) & $70.1 \pm 13.6 ;$ Median 68.8; (range 42.0-107.4) \\
\hline Mean/Median/Range & BMI & $27.1 \pm 13.2 ;$ Median 26.2; (range 15.4-55.8) \\
\hline Mean/Median/Range & BSA(M $\left.{ }^{2}\right)$ & $1.1 \pm 13.2 ;$ Median 1.8; (range 1.3-2.2) \\
\hline Marital status & Without Spouse & 62 & 34.4 \\
& With Spouse & 118 & 65.6 \\
\hline Income Sources & Non-Regular Income & 127 & 70.6 \\
& Regular Income & 53 & 29.4 \\
\hline Education Level & Below Secondary & 64 & 35.6 \\
& Secondary and Above & 116 & 64.4 \\
\hline Religion & Christian & 170 & 94.4 \\
& Muslim and Others & 10 & 5.6 \\
\hline Alcohol Use & No & 162 & 93.1 \\
& Yes & 12 & 6.9 \\
& Missing & 6 & 3.3 \\
\hline
\end{tabular}

Key: BMI-Body Mass Index; BSA- Body Surface Area

The mean age of the study participants was $43.4( \pm 13.2)$ years. Almost half $(49.4 \%)$ of them were aged between $41-65$ years and more than $60.0 \%$ had exceeded their ideal body weights [mean BMI, $27.1( \pm 13.2)]$. Over $60 \%$ of the study participants had attained at least secondary level of education. Over 90\% of the participants were Christians and a similar proportion were non-alcohol users (Table 1).

The clinical indications of warfarin anticoagulation among the patients are shown in Figure 1. 
Figure 1: Clinical Indications of Warfarin Therapy among the Study Participants ( $N=180)$

\section{Clinical Indication of warfarin anticoagulation}

Deep Venous Thrombosis (DVT)

$$
\text { Heart valve surgery }
$$

Rheumatic heart disease

Atrial fibrillation

Pulmonary embolism

Transient ischaemic attacks

0.0

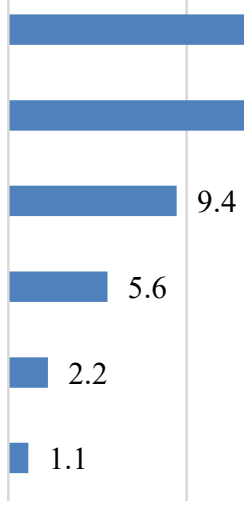

10.0

9.4
33.3

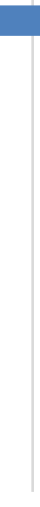

20.0

30.0

40.0

50.0
54.4

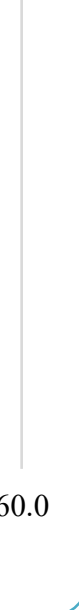

NB: Atrial fibrillation included the associated conditions such as thrombus in the heart, dilated cardiomyopathy, constrictive pericarditis, ischaemic heart disease and heart failure. Some patients had more than one clinical indication of anticoagulation

Over half (54.4\%) of patients were using warfarin due to deep vein thrombosis, while a third (33.3\%) had undergone heart valve replacement which required chronic anticoagulation. The remaining patients were prescribed warfarin due to rheumatic heart disease (9.4\%) and atrial fibrillation (5.6 \%) (Figure 1).

The details of warfarin therapy such as the initial, maintenance daily doses prescribed and the duration of use are presented in Table 2.

Table 2: Details of Warfarin Therapy among the Study Patients

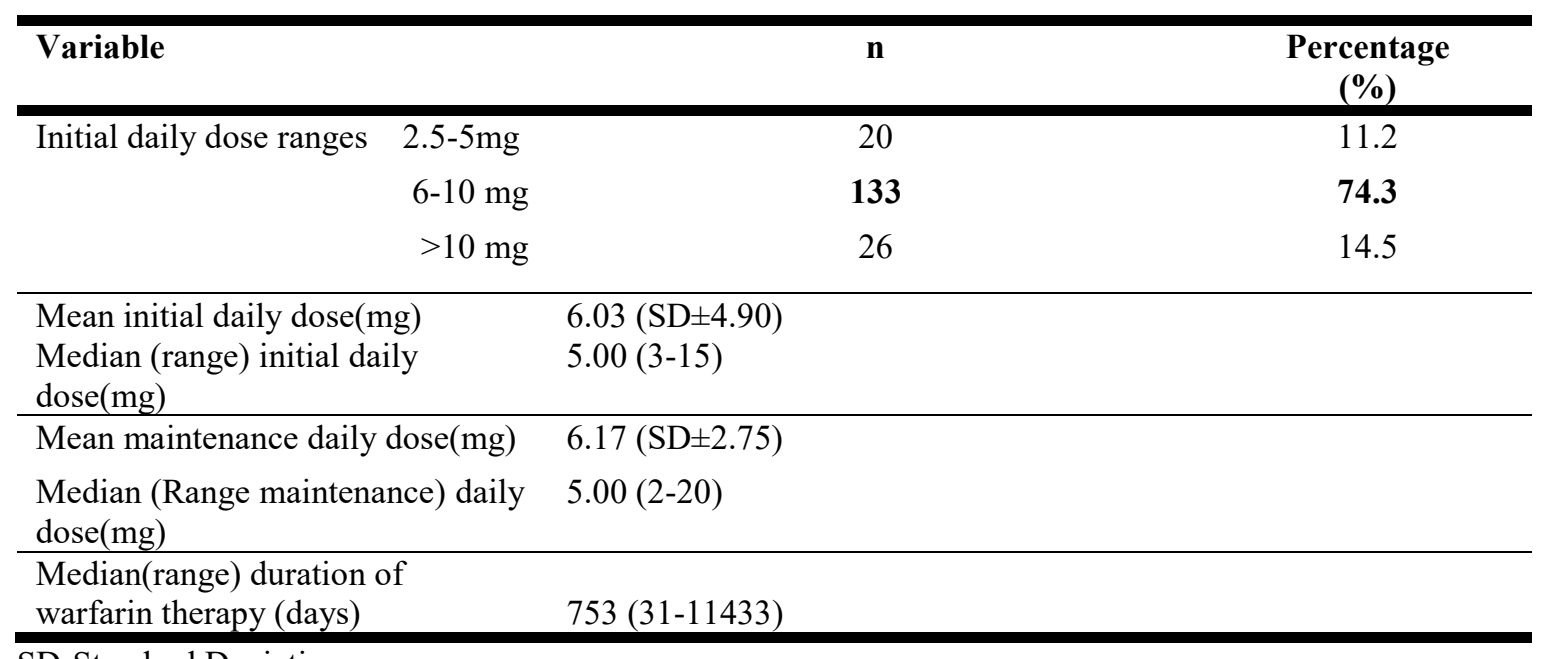


The mean initial and maintenance daily warfarin doses were $6.03 \mathrm{mg}( \pm 4.90)$ and $6.17 \mathrm{mg}( \pm 2.75)$, respectively. Almost three-quarters of the patients were initiated warfarin at $6-10 \mathrm{mg}$ per day for their clinical conditions. The remainder of the patients received initial daily doses of $\leq 5 \mathrm{mg}$ or more than $10 \mathrm{mg}$. The median duration of warfarin use was 753 days or approximately two years (Table 2).

One of the main outcome variables of this study was the prescribed warfarin maintenance doses by clinical indications of anticoagulation. These may be surrogate markers for the anticipated response (Figure 2).

Figure 2: Warfarin maintenance doses across the clinical indications

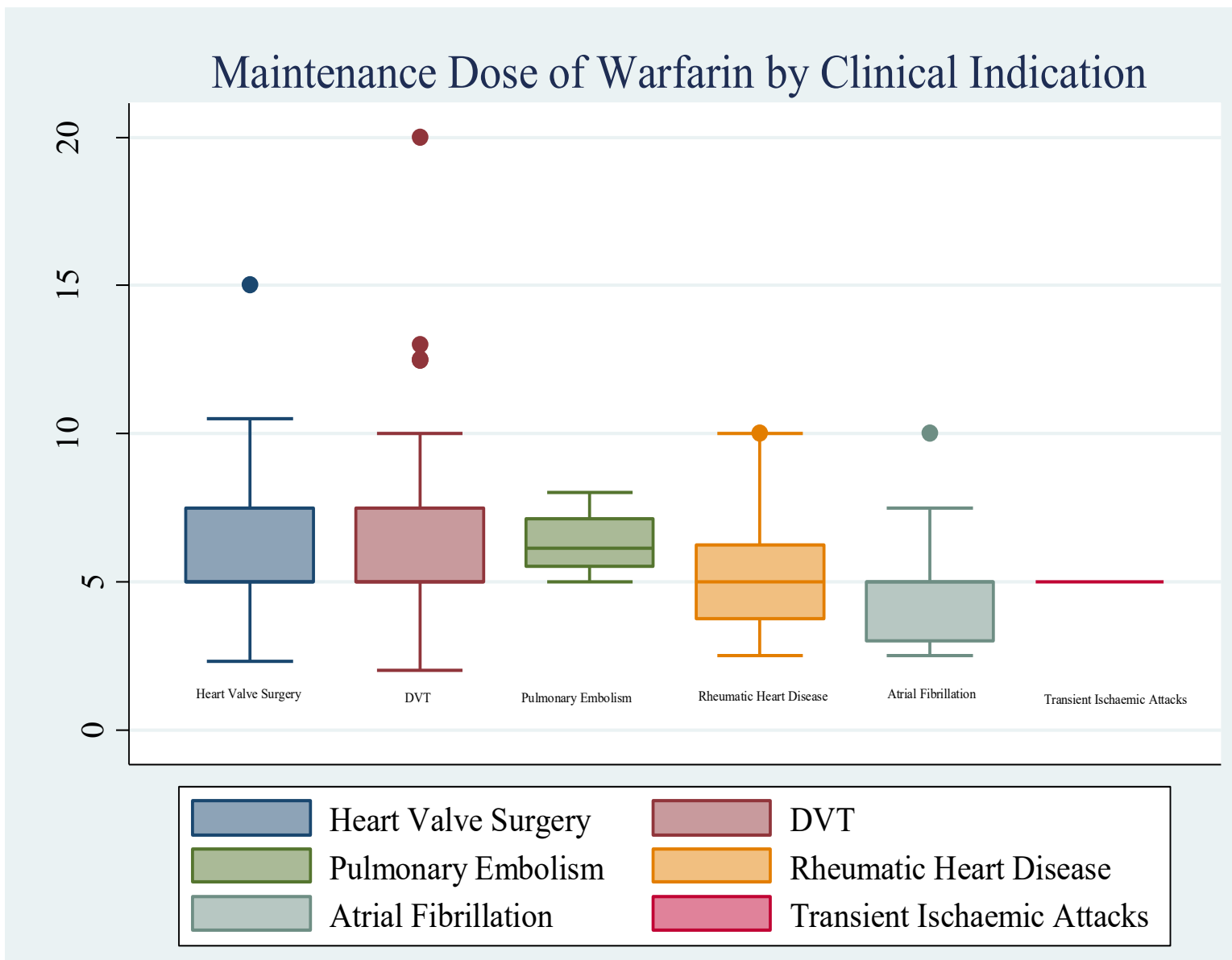

NB: DVT-Deep Vein Thrombosis. 
Higher mean warfarin daily maintenance doses (>5mg/day) were required in patients who had undergone heart valve surgery or suffering from venous thromboembolic disorders (Figure 2).

The majority of the patients (>50.0\%) were receiving warfarin maintenance doses ranging from 6 to $10 \mathrm{mg}$ per day across the clinical indications. Additionally, a significant proportion (15.5\%) of patients with DVT received warfarin maintenance doses higher than $10 \mathrm{mg}$ per day and none of the patients with pulmonary embolism received doses of less than $6 \mathrm{mg}$.

Patients were broadly classified into two categories depending on the clinical indication of coagulation disorders and for the ease of comparing variables. In this respect, one group of patients who had a diagnosis of rheumatic heart disease, atrial fibrillation or heart valve surgery and repair were collectively classified as "cardioembolic diseases". The other group of patients comprising any form of venous thromboembolic events including DVT, pulmonary embolism or thrombosis in the brain (transient ischemic attacks) was categorized as "vascular thromboembolic events".

Approximately a fifth of the patients $(21.3 \%)$ with cardioembolic diseases were maintained at warfarin daily doses of $2-5 \mathrm{mg}$. Slightly over seventy per cent of patients suffering from either vascular thromboembolic events or cardioembolic diseases were receiving warfarin maintenance daily doses of 6$10 \mathrm{mg}$. The proportion of patients with vascular thromboembolic events who were receiving warfarin maintenance daily doses of more than $10 \mathrm{mg}$ per day was almost twice that of cardioembolic diseases (14.9\% vs. $6.7 \%$ ). Table 3 shows the associations between the development of various thromboembolic disorders and participants sociodemographic characteristics. 
Table 3: Association between Sociodemographic Characteristics and Clinical Indications of Warfarin Anticoagulation ( $\mathrm{N}=180)$

\begin{tabular}{|c|c|c|c|c|c|}
\hline \multirow{3}{*}{ Variable } & \multirow{3}{*}{ Category } & \multicolumn{4}{|c|}{ Clinical indication of Warfarin use } \\
\hline & & \multicolumn{2}{|c|}{ Cardioembolic Diseases } & \multicolumn{2}{|c|}{ Vascular Thrombotic Events } \\
\hline & & $\begin{array}{l}\text { No } \\
\text { n (\%) }\end{array}$ & $\begin{array}{l}\text { Yes } \\
\text { n (\%) }\end{array}$ & $\begin{array}{l}\text { No } \\
\text { n (\%) }\end{array}$ & $\begin{array}{l}\text { Yes } \\
\text { n (\%) }\end{array}$ \\
\hline \multirow[t]{2}{*}{ Sex } & Male & $18(42.9)$ & 24(57.1) & $18(42.9)$ & $24(57.1)$ \\
\hline & Female & $85(61.6)$ & $53(38.4)$ & $40(29.0)$ & $98(71.0)$ \\
\hline \multicolumn{2}{|l|}{ Group Differences } & \multicolumn{2}{|c|}{$\chi^{2}(1,180)=4.62 ; \mathbf{P}=\mathbf{0 . 0 3 1 6}$} & \multicolumn{2}{|c|}{$\chi_{(1,180)}^{2}=2.84 ; \mathrm{P}=0.0921$} \\
\hline \multirow[t]{2}{*}{ Age } & 50 Years and Below & $69(52.7)$ & $62(47.3)$ & $46(35.1)$ & $85(64.9)$ \\
\hline & Above 50 Years & $34(69.4)$ & $15(30.6)$ & $12(24.5)$ & $37(75.5)$ \\
\hline \multicolumn{2}{|l|}{ Group differences } & \multicolumn{2}{|c|}{$\chi_{(1,180)}^{2}=4.07 ; \mathbf{P}=\mathbf{0 . 0 4 3 6}$} & \multicolumn{2}{|c|}{$\chi^{2}(1,180)=1.84 ; \mathrm{P}=0.1746$} \\
\hline \multirow[t]{2}{*}{ Body mass index } & Underweight/Normal & $19(32.8)$ & $39(67.2)$ & $27(46.6)$ & $31(53.4)$ \\
\hline & Overweight/Obese & $65(72.2)$ & $25(27.8)$ & $20(22.2)$ & $70(77.8)$ \\
\hline \multicolumn{2}{|l|}{ Group differences } & \multicolumn{2}{|c|}{$\chi_{(1,148)}^{2}=22.38 ; \mathbf{P}<\mathbf{0 . 0 0 0 1}$} & \multicolumn{2}{|c|}{$\chi_{(1,180)}^{2}=9.63 ; \mathbf{P}=\mathbf{0 . 0 0 1 9}$} \\
\hline \multirow[t]{2}{*}{ Marital status } & Without Spouse & $28(45.2)$ & 34(54.8) & $27(43.5)$ & $35(56.5)$ \\
\hline & With Spouse & $75(63.6)$ & $43(36.4)$ & $31(26.3)$ & 87(73.7) \\
\hline \multicolumn{2}{|l|}{ Group differences } & \multicolumn{2}{|c|}{$\chi_{(1,180)}^{2}=5.62 ; \mathbf{P}=\mathbf{0 . 0 1 7 8}$} & \multicolumn{2}{|c|}{$\chi_{(1,180)}^{2}=5.56 ; \mathbf{P}=\mathbf{0 . 0 1 8 4}$} \\
\hline \multirow[t]{2}{*}{ Employment status } & Non-Regular Income Earners & $72(56.7)$ & $55(43.3)$ & $40(31.5)$ & $87(68.5)$ \\
\hline & Regular Income Earners & $31(58.5)$ & $22(41.5)$ & $18(34.0)$ & $35(66.0)$ \\
\hline \multicolumn{2}{|l|}{ Group differences } & \multicolumn{2}{|c|}{$\chi_{(1,180)}^{2}=0.05 ; \mathrm{P}=0.8242$} & \multicolumn{2}{|c|}{$\chi^{2}(1,180)=0.10 ; \mathrm{P}=0.7469$} \\
\hline \multirow[t]{2}{*}{ Highest academic level } & Below Secondary Education & $36(56.3)$ & $28(43.8)$ & $22(34.4)$ & $42(65.6)$ \\
\hline & Secondary and Above & $67(57.8)$ & $49(42.2)$ & $36(31.0)$ & $80(69.0)$ \\
\hline \multicolumn{2}{|l|}{ Group differences } & \multicolumn{2}{|c|}{$\chi^{2}(1,180)=0.04 ; \mathrm{P}=0.8447$} & \multicolumn{2}{|c|}{$\chi_{(1,180)}^{2}=0.21 ; P=0.6462$} \\
\hline \multirow[t]{2}{*}{ Denomination } & Christian & $96(56.5)$ & $74(43.5)$ & $56(32.9)$ & $114(67.1)$ \\
\hline & Muslim and Others & $7(70.0)$ & $3(30.0)$ & $2(20.0)$ & $8(80.0)$ \\
\hline \multicolumn{2}{|l|}{ Group differences } & $\chi^{2}(1,180)=0$ & $=0.4007$ & $\chi^{2}(1,180)=$ & 0.3948 \\
\hline Tobacco use & No & $100(57.8)$ & $73(42.2)$ & $55(31.8)$ & $118(68.2)$ \\
\hline & Yes & $1(50.0)$ & $1(50.0)$ & $1(50.0)$ & $1(50.0)$ \\
\hline Group differences & & $\chi^{2}(1,175)=0$ & $=0.8242$ & $\chi^{2}(1,175)=$ & 0.5831 \\
\hline Alcohol Use & No & $93(57.4)$ & $69(42.6)$ & $52(32.1)$ & $110(67.9)$ \\
\hline & Yes & $7(58.3)$ & $5(41.7)$ & $4(33.3)$ & $8(66.7)$ \\
\hline Group differences & & $\chi^{2}(1,174)=0$ & $=0.9501$ & $\chi^{2}(1,174)=$ & 0.9296 \\
\hline
\end{tabular}

There were statistically significant associations between the gender and use of warfarin for prevention of cardioembolic diseases $(P=0.0316)$, with a slightly higher proportion of males utilizing the drug. A similar trend was observed in patients aged $\leq 50$ years who showed a statistically significant association with the development of cardioembolic diseases $(P=0.0436)$. A significant proportion $(67.2 \%)$ of patients with $B M I$ $\leq 25$ were anticoagulated because of cardiac related thrombosis $(p<0.0001)$, while $70(77.8 \%)$ patients with $\mathrm{BMI}>25$ received warfarin therapy for vascular thromboembolic events $(\mathrm{P}=0.0019)$. In addition, over 
half of patients, 34 (54.8\%) who were not living with spouses required warfarin anticoagulation because of cardioembolic diseases $(P=0.0178)$ and almost three-quarters, $87(73.7 \%)$ with spouses were anticoagulated for vascular related thrombotic events $(p=0.0184)$ (Table 3$)$.

Comorbidities may impact on warfarin anticoagulation. Whilst the majority of participants, $61.0 \%(n=110)$ did not have any comorbidities, $33 \%(n=59)$ and $6 \%(n=11)$ had one and two or more concomitant diseases, respectively (Figure 3). This warrants the use of concomitant medications and hence the potential for drug-drug interactions with warfarin.

Figure 3: Types of comorbidities among the study participants

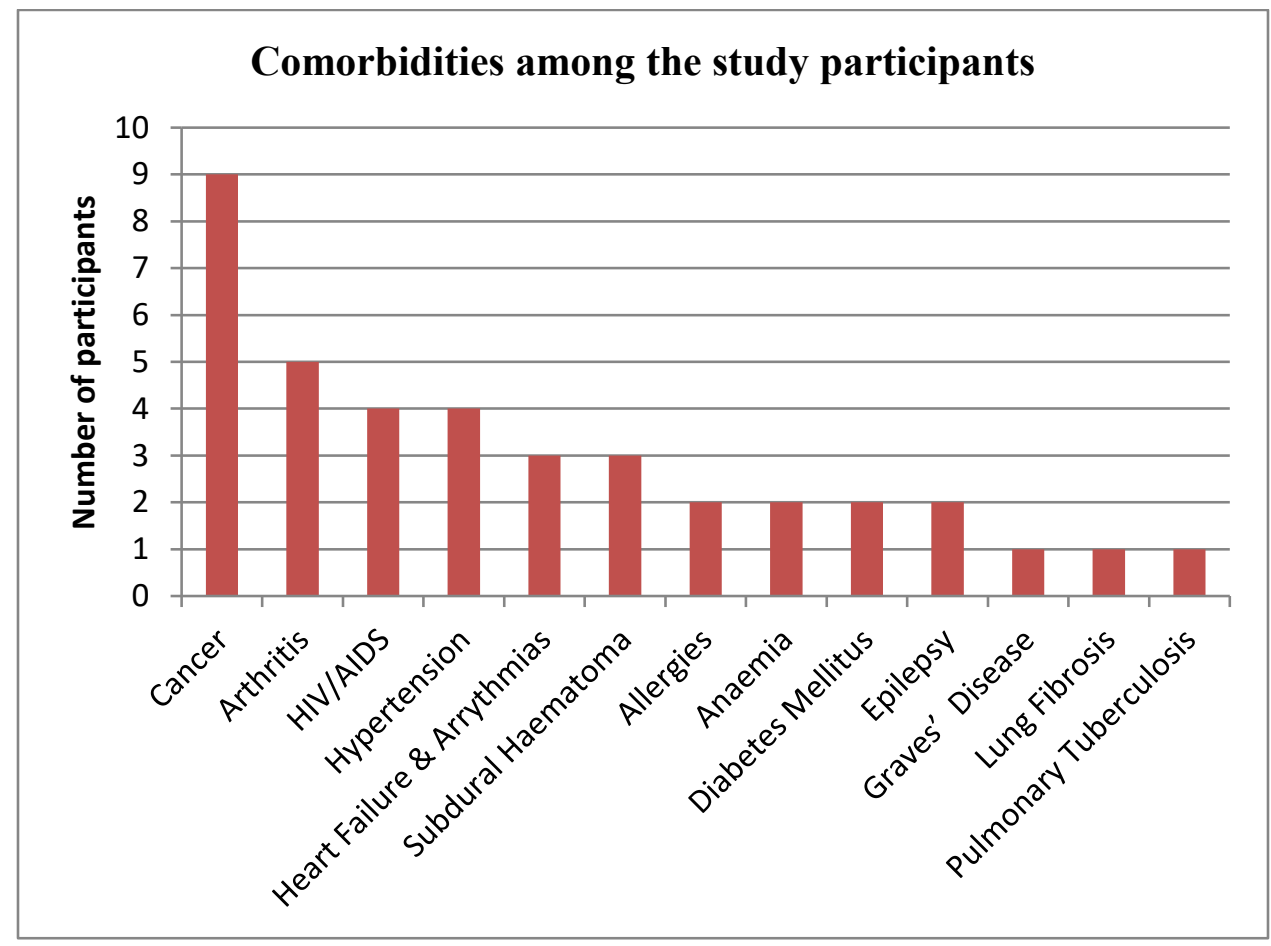

The most common comorbidity was cancer followed by arthritis and HIVIAIDS.

This study found that $45 \%$ ( $n=81)$ participants were also using other conventional medicines for treatment of comorbid illnesses. The classes of the other drugs used by the patients are shown Figure 4. 
Figure 4: Classes of conventional medicines used by the patients in the study population

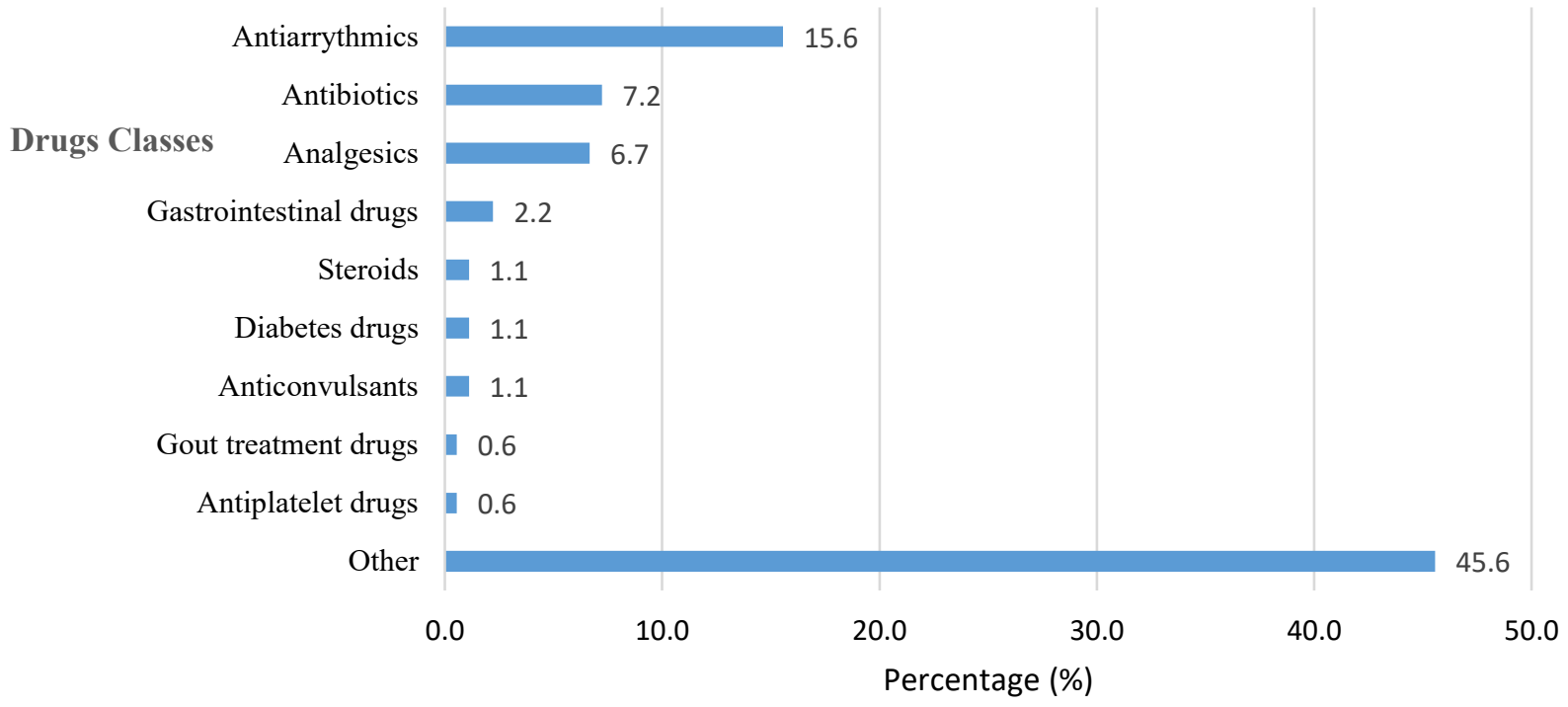

Antiarrythmics $(15.6 \%)$ were the most commonly used concomitant medications followed by antibiotics $(7.2 \%)$ and analgesics (6.7\%) (Figure 4$)$.

The classes of other drugs used by the participants are shown in figure 5 below.

Figure 5: Other drugs used by the participants

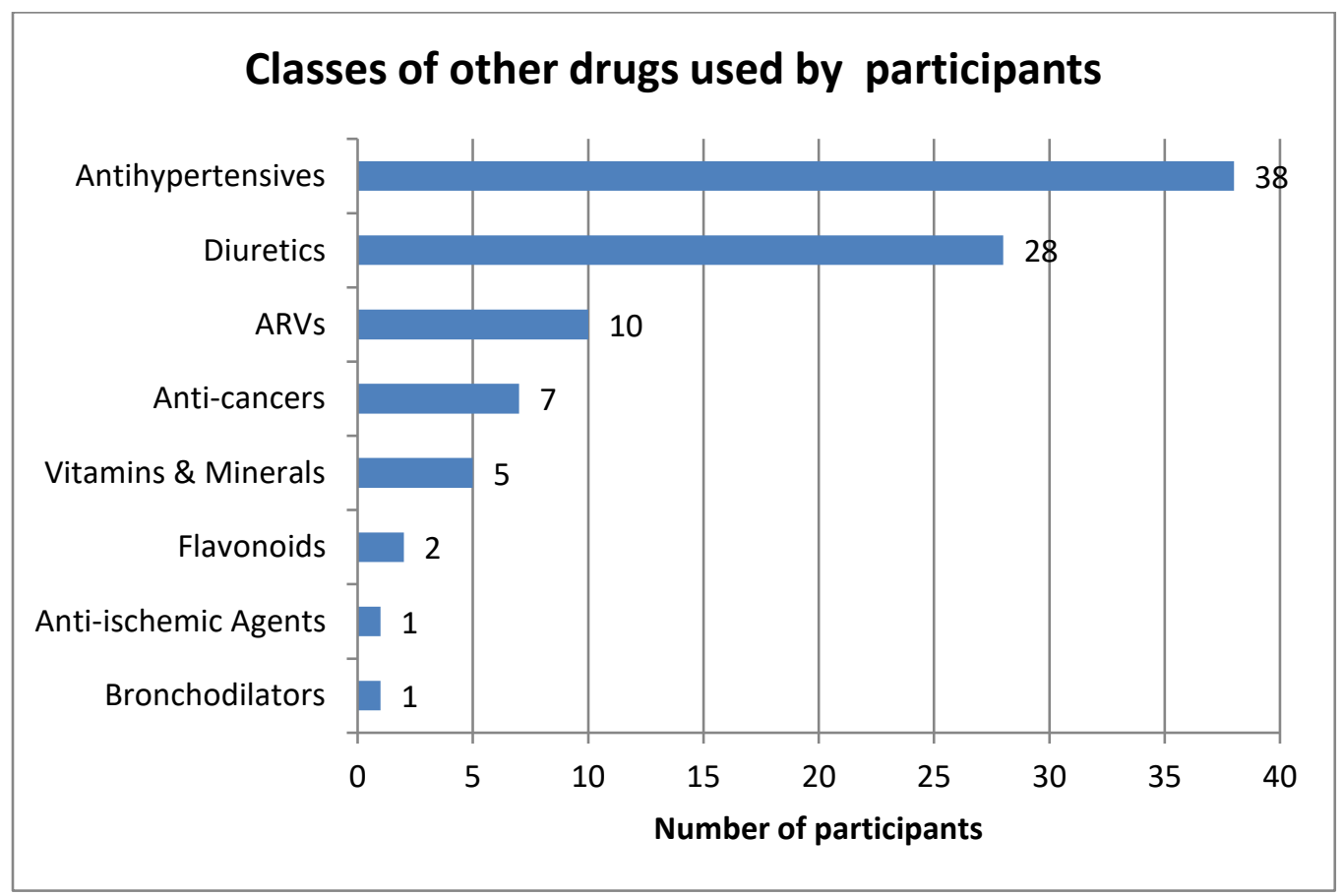

Note: Most of the participants were prescribed more than one class of drugs. 
The most commonly used other drugs were antihypertensives $(n=38)$ and diuretics $(n=28)$ (Figure 5).

\section{0: Discussion}

The majority of patients were females and in their middle age, with female predominance and a similar age distribution reported in other studies in Kenya $[9,20,22,34,37]$. The female preponderance may be reflective of the Kenyan health seeking behavior where more females than males seek health care [38]. Given the high percentage of women in our study, and a number at child bearing age, it may be beneficial to introduce contraceptive services as part of anti-coagulation services to benefit them [39].

Approximately half of the study participants were either overweight or obese, similar to findings from other African countries [40]. Whilst obesity has been linked to the development of thrombotic diseases [26], patients could have been overweight or obese when they first presented for anticoagulation or became overweight/obese whilst receiving anticoagulation therapy. However, determining the time to developing obesity and associated factors was beyond the scope of this study. This will be looked at further with ongoing efforts to improve the lifestyles of patients in Kenya through the 'Implementation of the NonCommunicable Disease 2015-2020' Government strategy to reduce high rates of overweight, obesity and cardiovascular disease $[30,41,42]$.

The median duration of warfarin therapy was approximately two years, implying that most of the patients had possibly been stabilized on treatment. However, we cannot say this with certainty without regular INR monitoring. The initiated dose of warfarin was typically $6-10 \mathrm{mg}$ per day, which deviate from international guidelines suggesting that patients should be started at $10 \mathrm{mg} /$ day unless there are special precautions [3]. These were not evident in our study, and we will be investigating this further in future research as our patients may be underdosed initially. The warfarin maintenance dose was at $6.17 \pm 2.75 \mathrm{mg}$ per day, similar to a previous study undertaken in the same setting at $6.81 \pm 2.67 \mathrm{mg}$ per day [43]. Generally few patients $(<10.0 \%)$ were receiving warfarin maintenance doses of $<5 \mathrm{mg}$ or $\geq 10 \mathrm{mg}$ per day. A larger proportion of patients with vascular related thrombotic events required $>5 \mathrm{mg}$ warfarin per day for maintenance doses compared to patients with heart conditions, corroborating findings from others in Kenya undergoing anticoagulation due to mechanical heart valves [43]. However, doses of warfarin in $\mathrm{KNH}$ were appreciably 
different from a Chinese population at $3.3 \pm 1.4 \mathrm{mg}$ per day [7]. We believe these differences could be attributable to genetic and environmental variations between the two populations; however, further studies are needed before we can say this with certainty.

The major clinical indications of warfarin anticoagulation among the study patients were vascular and cardiac thromboembolism, principally VTEs, similar to other studies in Kenya [9,21], although this is not always the case $[19,20,37]$. Specifically, Karuri et al found a higher prevalence of VTEs at $82.5 \%$ and a lower proportion of patients with heart diseases at 7.6\% [37]. However, all studies showed that VTEs were among the common clinical indications for warfarin anticoagulation among patients in Kenya. Typically in the published studies, the proportion of patients suffering from VTEs was higher than cardioembolic diseases suggesting that warfarin is typically prescribed for the management of DVT and pulmonary embolism in the Kenyan healthcare settings. This compares with mechanical heart valves being the principal reason among Tanzanian and Botswana patients followed by DVT $(26.8 \%)[44,45]$ among other African countries.

We found out that the proportion of males with cardioembolic diseases was statistically significantly higher than females, similar to other published studies [46]. There were though more females with vascular thromboembolic events compared to males in our study. However, this was not statistically significant despite other studies suggesting a higher number of females at risk for VTEs [47]. We will be investigating this further in future studies. There was also a slightly larger proportion of patients $\leq 50$ years with a diagnosis of cardioembolic disease in our study principally due to valvular abnormalities as a result of rheumatic heart disease. This is perhaps not surprising since studies in LMICs have revealed that valvular abnormalities occur more often in young and middle aged persons [48]. Patients with cardioembolic diseases in our study appeared to have been underweight or normal weight whereas those with vascular thromboembolic events such as DVT were overweight or obese. Whilst our study was not intended to find potential risk factors for VTEs, the degree of obesity has been linearly linked to the development of thrombotic events similar to our findings [25-27]. In addition, the development of valvular heart disease was not correlated to obesity status; however, patients in our study were generally normal 
or underweight suggesting that these patients may have lost weight over time due to the chronicity of their disease conditions. However, we cannot say this with certainty and will be following this up in future research projects.

Overall, we found out that patients with VTEs were generally of older age and perhaps married whilst those with cardioembolic diseases were generally young and perhaps were not married at the time of study. The proportion of males suffering from cardioembolic diseases were also more than that of females. We are not sure of the reasons behind these findings, but will be monitoring the situation in the future to assess any implications for the future management of these patients.

Several comorbidities have been shown to impact on the development of vascular thromboembolism disorders [49]. We found that approximately two-fifths of patients in our study had at least one other disease which were not limited to hypercoagulable states [50]. Commonly co-prescribed conventional medicines have also been shown to interact with warfarin [51]. However, less than half of the patients in our study were prescribed at least one other medicine apart from warfarin. The principal co-prescribed medicines were antiarrythmics probably for the management of atrial fibrillation. Antihypertensives and diuretics were also commonly prescribed for the management of heart failure and hypertension.

We are aware of a number of limitations with this study. The main one was difficulty in retrieving all patients' information from the files because of the way the information is archived. However, we tried to obtain as much information as possible. Secondly, as common with cross-sectional studies involving interviews, patients could have over-stated or under-stated their experiences. The data also represents what was occurring at one point in time and may not be reflective of the patient profiles over the years. Finally, due to resource constraints we were unable to undertake any pharmacogenetic testing as this is not funded within public hospitals in Kenya. We also did not undertake routine monitoring of prothrombin time-INRs due to resource issues within the public healthcare system in Kenya. We will seek to redress this in future studies. Never-the-less, we believe our findings will provide direction for the future.

\section{0: Conclusion and Recommendations}

Warfarin anticoagulation therapy among Kenyan patients is mainly for the treatment of cardioembolic and venous thromboembolic diseases presenting with few comorbidities and concomitant medicines. Within the anticoagulation clinic population in our study, young lean males were more likely to have cardioembolic disorders whereas VTEs afflict females who have elevated BMI's. Clinicians should be 
aware that patients with VTE generally require higher warfarin maintenance doses than those with cardioembolic disorders. Further studies should correlate patients' profiles with warfarin response as measured by INR levels in addition to pharmacogenetics. We will be looking to undertake warfarin pharmacogenetic studies in future research projects following funding,

\section{Key Issues}

- The majority of Kenyans receiving long-term warfarin therapy are in their middle-ages, which are the highly economically productive years of the population. Early prevention and optimal management of the coagulation disorders may subsequently increase productivity among the affected population.

- Anticoagulation management among patients in Kenya is essentially for venous or cardiac related thromboembolic disorders.

- Cardioembolic disorders are significantly more common in lean males aged $\leq 50$ years whilst venous thromboembolic disorders are principally seen in females and obese individuals. Clinicians should be aware that obesity may aggravate the management of venous thromboembolic events.

- Kenyan patients, especially those with venous thromboembolic events, require high daily maintenance doses of warfarin.

- The significant association of the marital status and the development of VTEs or cardioembolic events require further research.

\section{Acknowledgements}

The authors acknowledge all staff at anticoagulation clinics of $\mathrm{KNH}$ for the immeasurable support during the study. The authors also acknowledge all patients who willingly participated in the study.

\section{Conflict of interest}

Authors declare no conflict of interest.

\section{Authors' Contributions}

DN conceptualized the idea, wrote the concept, collected and analyzed the data and drafted the manuscript. AG assisted with proposal development, data analysis and interpretation as well as writing the manuscript. GO and EA reviewed the proposal, data analysis and revised the manuscript, with BBG helping with the data analysis and the manuscript review.

\section{Data availability}

Datasets used are available on request (Email: dgnyamu@gmail.com)

\section{Funding Statement}

This work was entirely self-funded by the corresponding author.

\section{References}

‘*' - of interest, or “**” - of considerable interest

1. Johnson MJ, Sproule MW, Paul J. The prevalence and associated variables of deep venous thrombosis in patients with advanced cancer. Clinical oncology. 1999;11(2):105-10.

2. Abdel-Aziz A, Elfawwal MA. Incidence of Deep Venous Thrombosis in Stroke Patients in Medical Intensive Care Unit Zagazig University Hospitals, Egypt. Zagazig Univ Med J. 2015;20(1),88-96. 
3. Ageno W, Gallus AS, Wittkowsky A et al. Oral anticoagulant therapy: Antithrombotic Therapy and Prevention of Thrombosis, 9th ed: American College of Chest Physicians Evidence-Based Clinical Practice Guidelines. Chest. 2012;141(2 Suppl):e44S-e88S.

4. Lowery S, Haley K, Bussey HI. Oral anticoagulation: challenges in the case-management setting. Lippincott's case management. 2005;10(1):39-50.

5. Holbrook AM, Pereira JA, Labiris R et al. Systematic overview of warfarin and its drug and food interactions. Archives of internal medicine. 2005;165(10):1095-106.

${ }^{*}$ Key study regarding warfarin and its uses

6. Camm AJ, Lip GY, De Caterina R et al. 2012 focused update of the ESC Guidelines for the management of atrial fibrillation: an update of the 2010 ESC Guidelines for the management of atrial fibrillation. Developed with the special contribution of the European Heart Rhythm Association. European heart journal. 2012;33(21):2719-47.

7. Yu HC, Chan TY, Critchley JA et al. Factors determining the maintenance dose of warfarin in Chinese patients. QJM. 1996;89(2):127-35.

8. Aguilar MI, Hart R. Oral anticoagulants for preventing stroke in patients with non-valvular atrial fibrillation and no previous history of stroke or transient ischemic attacks. The Cochrane database of systematic reviews. 2005(3):Cd001927.

9. Manji I, Pastakia SD, Do AN et al. Performance outcomes of a pharmacist-managed anticoagulation clinic in the rural, resource-constrained setting of Eldoret, Kenya. Journal of thrombosis and haemostasis. 2011;9(11):2215-20.

*Interesting early study from kenya

10. Generalova D, Cunningham S, Leslie SJ et al. A systematic review of clinicians' views and experiences of direct-acting oral anticoagulants in the management of nonvalvular atrial fibrillation. British journal of clinical pharmacology. 2018;84(12):2692-703.

11. Kim IS, Kim HJ, Kim TH et al. Non-vitamin K antagonist oral anticoagulants have better efficacy and equivalent safety compared to warfarin in elderly patients with atrial fibrillation: A systematic review and meta-analysis. Journal of cardiology. 2018;72(2):105-12.

12. Kamali F. Genetic influences on the response to warfarin. Current opinion in hematology. 2006;13(5):357-61.

13. Tang Q, Zou H, Guo C, Liu Z. Outcomes of pharmacogenetics-guided dosing of warfarin: a systematic review and meta-analysis. International journal of cardiology. 2014;175(3):587-91.

14. Loebstein R, Yonath $\mathrm{H}$, Peleg $\mathrm{D}$ et al. Interindividual variability in sensitivity to warfarin--Nature or nurture? Clinical pharmacology and therapeutics. 2001;70(2):159-64.

15. Sconce EA, Kamali F. Appraisal of current vitamin $\mathrm{K}$ dosing algorithms for the reversal of overanticoagulation with warfarin: the need for a more tailored dosing regimen. European journal of haematology. 2006;77(6):457-62.

16. Makohusova M, Mrazova V, Bednarova A et al. Comparison of Two Different Techniques Of Warfarin Dosing Determination - A Chemometrics Study. Iran J Pharm Res. 2019;18(2):1010-9.

17. Jorgensen AL, Prince C, Fitzgerald G et al. Implementation of genotype-guided dosing of warfarin with point-of-care genetic testing in three UK clinics: a matched cohort study. BMC medicine. 2019;17(1):76.

18. Ogendo SW. Warfarin-related bleeding following open heart surgery in Nairobi. East Afr Med J. 2001;78(3):139-43.

19. Kibiru A. Adequacy of oral anticoagulation therapy among ambulatory patients at Kenyatta National Hospital. Nairobi. 2012. Available at URL:

http://erepository.uonbi.ac.ke/bitstream/handle/11295/8262/Kibiru Adequacy\%20of\%200ral\%20Anti\%20 coagulation\%20Therapy\%20Among\%20Ambulatory\%20Patients $\% 20$ at $\% 20$ the $\% 20$ Kenyatta $\% 20$ National $\% 20$ Hospital\%2c\%20Nairobi.pdf?sequence=1\&isAllowed=y.

20. Mariita K, Nyamu DG, Maina CK et al. Patient factors impacting on oral anticoagulation therapy among adult outpatients in a Kenyan referral hospital. Afr. J. Pharmacol. Ther. 2016; 5(3): 193-200

*Interesting study assessing possible patient related factors regarding warfarin use

21. Mariita K, Nyamu D, Maina C et al. Patient Associated Factors that Affect Adherence to Warfarin Therapy in a Tertiary Referral Hospital in Kenya. East Cent Afr J Pharm Sci. 2015;18:67-74

${ }^{* *}$ Good study assessing possible patient related factors regarding warfarin use 
22. Nyamu DG, Guantai AN, Osanjo GO et al. Predictors of Adequate Ambulatory Anticoagulation among Adult Patients in a Tertiary Teaching and Referral Hospital in Kenya. Afri J. of Pharmacol and Ther. 2017; 24;6(1);20-26.

${ }^{* *}$ Earlier study providing a benchmark for the current study

23. Nyamu GD, Guantai AN. Patterns of Ambulatory Anticoagulation Practices in a County Hospital in Nairobi. PJK. 2018. 23(3): 75-82.

24. Iqbal S. Effect of a Designed Warfarin Based Education Program on Patients' Knowledge and Anticoagulation Control among Adult Outpatients Attending Clinics at Kenyatta National Hospital. 2017. Available at URL: https://pdfs.semanticscholar.org/8c9e/ed087e09babf640154648cd45921c41d9d4d.pdf. 25. Anderson FA, Jr., Spencer FA. Risk factors for venous thromboembolism. Circulation. 2003;107(23 Suppl 1):19-16.

26. Hansson PO, Eriksson $\mathrm{H}$, Welin $\mathrm{L}$ et al. Smoking and abdominal obesity: risk factors for venous thromboembolism among middle-aged men: "the study of men born in 1913". Archives of internal medicine. 1999;159(16):1886-90.

27. Stein PD, Beemath A, Olson RE. Obesity as a risk factor in venous thromboembolism. The American journal of medicine. 2005;118(9):978-80.

28. Mkuu RS, Epnere K, Chowdhury MAB. Prevalence and Predictors of Overweight and Obesity Among Kenyan Women. Preventing chronic disease. 2018;15:E44.

29. Mbochi RW, Kuria E, Kimiywe $\mathrm{J}$ et al. Predictors of overweight and obesity in adult women in Nairobi Province, Kenya. BMC public health. 2012;12:823.

30. Amugsi DA, Dimbuene ZT, Mberu B et al. Prevalence and time trends in overweight and obesity among urban women: an analysis of demographic and health surveys data from 24 African countries, 1991-2014. BMJ open. 2017;7(10):e017344.

31. Obulutsa JN. RURAL URBAN PREVALENCE AND ASSOCIATED FACTORS OF OVERWEIGHT AND OBESITY IN ADULT PATIENTS SEEKING HEALTHCARE: A CASE OF PCEA KIKUYU HOSPITAL, KENYA. 2015. Available at URL: https://pdfs.semanticscholar.org/c406/1ea228749d55f04d215b8b06c53dad867e7e.pdf.

32. Kanyi J, Karwa R, Pastakia SD et al. Venous Thromboembolism Requiring Extended Anticoagulation Among HIV-Infected Patients in a Rural, Resource-Constrained Setting in Western Kenya. The Annals of pharmacotherapy. 2017;51(5):380-7.

33. Aregbeshola BS, Khan SM. Out-of-Pocket Payments, Catastrophic Health Expenditure and Poverty Among Households in Nigeria 2010. International journal of health policy and management. 2018;7(9):798-806.

34. Mapa-Tassou C, Katte JC, Mba Maadjhou C et al. Economic Impact of Diabetes in Africa. Current diabetes reports. 2019;19(2):5.

35. Cameron A, Ewen M, Ross-Degnan D et al. Medicine prices, availability, and affordability in 36 developing and middle-income countries: a secondary analysis. Lancet. 2009;373(9659):240-9.

36. Barlett JE, Kotrlik JW, Higgins CC. Organizational research: Determining appropriate sample size in survey research. Inf Technol Learn Perform J. 2001;19(1):43.

37. KARURI SW, NYAMU DG, OPANGA SA et al. Factors Associated with Time in Therapeutic

Range among Patients on Oral Anticoagulation Therapy in a Tertiary Teaching and Referral Hospital in Kenya. East and Central African Journal of Pharmaceutical Sciences 2019; 22: 85-95.

${ }^{*}$ Key study regarding the use of warfarin among patients in Kenya

38. Voeten HA, O'Hara H B, Kusimba J et al. Gender differences in health care-seeking behavior for sexually transmitted diseases: a population-based study in Nairobi, Kenya. Sexually transmitted diseases. 2004;31(5):265-72.

39. Bernard C, Pekny C, Omukagah CO et al. Integration of contraceptive services into anticoagulation management services improves access to long-acting reversible contraception. Contraception. 2018;98(6):486-91.

40. Cois A, Day C. Obesity trends and risk factors in the South African adult population. BMC obesity. 2015;2:42.

41. MoH. Republic of Kenya Ministry of Health. KENYA NATIONAL STRATEGY FOR THE PREVENTION AND CONTROL OF NON-COMMUNICABLE DISEASES 2015 to 2020. Available at URL: http://www.who.int/nmh/ncd-task-force/kenya-strategy-ncds-2015-2020.pdf 
42. Mbui JM, Oluka MN, Guantai EM et al. Prescription patterns and adequacy of blood pressure control among adult hypertensive patients in Kenya; findings and implications. Expert review of clinical pharmacology. 2017;10(11):1263-71.

43. Ogendo SW. Pattern of anticoagulation control after heart valve surgery at the Kenyatta National Hospital, Nairobi. East Afr Med J. 2000;77(7):354-8.

44. Makubi A, Lwakatare J, Nordrehaug J et al. Anticoagulant control results among patients with mechanical heart valves at Muhimbili National Hospital, Tanzania. Tanzan Med J. 2008; 23(1):12-15.

45. Mwita JC, Francis JM, Oyekunle AA et al. Quality of Anticoagulation With Warfarin at a Tertiary Hospital in Botswana. Clinical and applied thrombosis/hemostasis. 2018;24(4):596-601.

46. Aranki SF, Rizzo RJ, Couper GS et al. Aortic valve replacement in the elderly. Effect of gender and coronary artery disease on operative mortality. Circulation. 1993;88(5 Pt 2):li17-23.

47. Rogers SO, Jr., Kilaru RK, Hosokawa P et al. Multivariable predictors of postoperative venous thromboembolic events after general and vascular surgery: results from the patient safety in surgery study. J Am Coll Surg. 2007;204(6):1211-21.

48. Lung B, Vahanian A. Epidemiology of valvular heart disease in the adult. Nature reviews Cardiology. 2011;8(3):162-72.

49. Watson T, Shantsila E, Lip GY. Mechanisms of thrombogenesis in atrial fibrillation: Virchow's triad revisited. Lancet. 2009;373(9658):155-66.

50. Chan MY, Andreotti F, Becker RC. Hypercoagulable states in cardiovascular disease. Circulation. 2008;118(22):2286-97.

51. Serlin MJ, Breckenridge AM. Drug interactions with warfarin. Drugs. 1983;25(6):610-20. 